\title{
Power, social exclusion and the "good life": the importance of measuring what really counts
}

\author{
Giulia Greco \\ Assistant Professor, Department for Global Health and Development, London School of \\ Hygiene and Tropical Medicine, London, UK
}

Marmot's (2015) The Health Gap takes the reader on a fascinating roller coaster tour across times, places and disciplines, to investigate the association between inequality and health. The life-expectancy gaps and health inequalities across and within nations signal that there is a substantial difference in the conditions in which people are born, grow, live, work and age. The book discusses five areas across the life cycle: early childhood development, education, employment, resilient communities, and older people. Marmot invites the reader to investigate the 'causes of the causes': why people have ill-health? Why people die? The crosscutting theme in the book, and one of the causes of the causes, is empowerment (or lack of). In this paper I will discuss the issues of power, social exclusion and hopelessness: "Social exclusion is not an all-or-nothing phenomenon. Degree of social exclusion and disempowerment can contribute to the social gradient in health ... in all our communities" (Marmot 2015, p. 230). The discussion will draw on two examples from my research: a community-based maternal health programme in Malawi; and a sexual health clinic for women at high risks of HIV in Kampala, Uganda.

\section{Maternal health and women's groups in rural Malawi}

Chapter 1 of The Health Gap provides the example of women dying in childbirth, and the shocking figure of the difference in lifetime risk of dying of a maternity-related cause between girls from Sierra Leone and Italy: 1 in 21 vs 1 in 17,100 (World Bank 2014). Over thirty years ago, at the launch of the Safe Motherhood Initiative in Nairobi, Professor Mahmoud Fathalla introduced the idea of a maternal death road: "a virtual treacherous slippery road, with millions of women in developing countries marching along it looking for safety exits" (Fathalla 2012, p. 3). Along the road there are exits that could save women's lives, but these exits are 
blocked by several barriers. The metaphor of the death road was effectively illustrated in a video produced by the WHO ('Why did Mrs X die?') ${ }^{1}$. The video is effective in depicting the human tragedy of a maternal death, through going deeper to identify the causes of the causes, tracing backward the steps of a mother ( $M r s ~ X)$ from a low-income country who has died while giving birth. Mrs $\mathrm{X}$ died in a hospital because of antepartum haemorrhage. However, had the hospital had more blood available for transfusion, she might have been saved. Had the hospital had an obstetrician and anaesthetist available, she might have had a timely caesarean section that could have prevented her death. Mrs X took four hours to reach hospital when she started bleeding. If emergency services were readily available in the village, or if she had access to antenatal care to detect and treat anaemia, her life could have been saved. Going back further, looking at her reproductive health history and socio-economic status, Mrs X never used family planning methods and, therefore, her pregnancies (seven) were not adequately spaced: too soon, too many, too close, and too late in life. Her body was weak, she was malnourished, she was the illiterate wife of a subsistence farmer. She had no choices, she was disempowered, and the safety exits in the road to maternal death were all blocked. Inspired by the Safe Motherhood movement, many initiatives tackled maternal deaths from the root causes: women's disempowerment. Some of my early research was on the evaluation of a community-mobilisation intervention to reduce maternal and neonatal mortality in rural Malawi: the Maimwana Project (Rosato et al. 2011). Central to the Maimwana Project are the women's groups which operate with a four-stage communitybased action cycle: 1 ) women gather together and engage in debates where they identify and prioritise health problems and needs; 2 ) develop locally feasible and sustainable strategies to address these issues; 3 ) implement their strategies with locally available resources; 4) and collectively evaluate them. Each women's group is facilitated by a trained volunteer member of the local community who guides the participants of the group and their communities through the action cycle. The mechanism which underlies the action cycle is driven by selfawareness of ill-health, community empowerment, participation and local mobilisation (Rosato et al. 2008, Rosato et al. 2006). In rural Malawi, the groups identified anaemia and malnutrition as two of the main threats to maternal health, and the groups set up communal vegetable gardens to improve and diversify their diet. Excess production from these agricultural activities was then sold to generate income. The groups also identified diarrhoea and malaria as two of the major threats to the survival of their new-born children. They 
engaged with other members of the community and with the local authorities for building wells for clean and safe water, for working towards a cleaner (malaria-free) environment and for obtaining subsidised bed nets. The groups also recognised the dangers of delivering at home and the importance of being assisted by a skilled health worker during birth. The groups lobbied the local authorities and donors and consequently several mobile, antenatal and under-5 clinics were established, bicycle-ambulances purchased, and traditional birth attendants trained. Because of these efforts, maternal mortality and neonatal mortality rates in the villages where women's groups were formed fell by $74 \%$ and $41 \%$ respectively (Lewycka et al. 2013). As Marmot states, "[f]or people with less money and privilege, and particular for families, community is where life happens, death too" (Marmot 2015 p. 255). MaiMwana Project women's groups are a successful example of how empowered women and communities can provide safety exits for pregnant women who, due to their socio-economic conditions, are likely walking down the maternal death road.

Marmot also discusses education as one of the key social determinants of health. Education is indeed a critical "enabler" to escape the poverty trap, intergenerational poverty and inequality. However, education and knowledge "is but one step to empowerment" (p. 62), and as a single strategy is sometimes not sufficient to enable people to climb up the social mobility ladder. In countries where the unemployment rate is very high (such as Uganda and many other sub-Saharan countries), even a university degree does not guarantee an escape from poverty. And even when they secure a job, graduated students from one of the most prestigious universities can expect to get a salary in the range of $£ 100$ to $£ 200$ per month ${ }^{2}$. Low pay led to a strike of health workers in Uganda in November 2017 - salaries for newly qualified doctors are 1.1 million shillings per month (just over $£ 200$ ).

\section{Female sex workers and disempowerment in Kampala, Uganda}

For the last year I have focused my research on women's capabilities at a sexual health clinic in Kampala: the Good Health for Women project. The clinic provides health care services free at the point of use for women at high risk of contracting HIV and other sexually transmitted diseases. Most of the patients attending the clinic are women engaged in commercial sex (Vandepitte et al. 2011). As part of the study, I collected information on the women's 
perspectives on what constitute a good life, and their hopes and aspirations. Preliminary results suggest that women who engage in commercial sex in Kampala have diverse socioeconomic backgrounds, but share a similar status of powerlessness, and lack of hope and aspirations for the future. Some women hold a university degree, many are illiterate. The majority are single mothers, and have been victims of violence perpetrated by clients, their partners, and in the past by their relatives and teachers. Each have their unique life story. One woman is a well-respected traditional leader in a village in Kenya, but she needs extra cash to sustain her extensive family. She wouldn't engage in commercial sex in her own or neighbouring communities, for the fear of losing her respected status. She travels to Kampala regularly, to earn that extra cash in the streets and bars. Another woman has a university degree and an office job, but her wage was not enough, or paid regularly. She quit that job and ended up becoming a sex worker. She has hopes of setting up her own business; she has the skills but lacks the capital for a successful start-up. Many are the women who migrated from rural areas to the city, in search of waged labour, and often already in a position of disempowerment. They were brought into town with the promise of better opportunities for education, employment, or marriage. They might have started working as housemaids, but things did not go as planned: an unexpected pregnancy, a breakdown of a relationship, debts. In addition, women fear going back to their villages, because of the shame attached to "returnees", as a sign of failure, and the stigma around prostitution. It emerged from this and other studies, that different pathways to prostitutions have in common a condition of powerlessness and gender inequity (Mbonye et al. 2012). It is particularly evident during negotiations for safer sex with a client, when the woman is often unable to protect herself from violence and HIV, as well as other diseases. Often, sex workers have to accept unprotected sex because of fear of violence, or because they are in desperate financial needs. For these women, a "good life" is having enough money to pay rent, feed their children, and pay school fees. Whatever hope they have, it is not for them, but for their children so that one day the children will be able to take care of them in return. This study amongst women attending the sexual health clinic exemplifies what Marmot argues in Chapter 2-that people with limited control over their lives are not able to make choices to keep themselves safe and healthy. 
The Good Health for Women project does not only offer HIV and STDs testing and treatment but is also tackling the social conditions of women engaged in commercial sex. It offers counselling to boost women's confidence and self-esteem, and improve their mental health, it offers antenatal and under 5 clinics, and a strong network of peer educators. Some satellite initiatives have also provided skilled training and vocational training (e.g. IT and tailoring) as a way out of poverty.

These two examples further add to the evidence provided by Marmot on how ill-health, and gender inequality, are caused by material, psychosocial and political disempowerment, and that empowerment, having real freedoms or choices, is a crucial determinant of health.

\section{A defence of health economics}

While there is much to agree with, I wish to conclude with a defence of economists (and health economists). In Chapter 3, Marmot feels "aghast" about using economic evaluation techniques to assess the value for money of a health policy, such as cost-benefit analysis which measures benefits in dollar terms. Health economists do generally agree that valuing a human life in monetary terms is not ideal (Coast 2004, Coast, Smith, and Lorgelly 2008, Smith et al. 2012, Greco, Lorgelly, and Yamabhai 2016); thus they are developing and have developed other techniques such as cost-effectiveness and cost-utility analyses which measure outcomes in years of life gained, adjusted for the quality of those years, or natural units, such as cases of violence or HIV averted by the programme. Moreover, health economists do consider equity issues alongside economic evaluation of health programmes, they seek to understand both equity and efficiency to aid the decision-making process on where, when, and how to invest public money (Sassi, Archard, and Le Grand 2001, Cookson, Drummond, and Weatherly 2009). We cannot deny that resources (human, financial, natural, and physical) are limited and, therefore efficiency is paramount. We need to understand how to get the most out these resources, to get the most benefits. The big question is how to identify, measure, and value these benefits. It would be unethical not to do so, to waste money that could help improve human well-being. Perhaps it is the narrow definition of benefits that Marmot feels aghast by rather than the drive to make the best use of money. Some economic studies have investigated what people value in life, what is important for 
them. And people value different aspects of life, not only health. They value family, friends, the community, their jobs, financial security, free time (Coast 2004, Grewal et al. 2006). Health is considered important per se, but often on instrumental grounds, as a means to achieve something else (Greco et al. 2015). A study from South Africa reported that health ranks 7 in the top aspects of a "good life", where the first three places are occupied by job, housing and education (Clark 2003). For these reasons, new interesting research is trying to further advance economic evaluation techniques to include broader aspects of life, subjective well-being or capabilities (Coast, Kinghorn, and Mitchell 2015, Simon et al. 2013, Anand and Dolan 2005, Greco, Skordis-Worrall, and Mills 2018, Peasgood et al. 2014, Brazier and Tsuchiya 2015). The ultimate goal would be to use the same unit of value (e.g. units of subjective well-being, or capabilities) to assess policies across sectors: which programmes are expanding people's capabilities? What are those interventions that make people more satisfied with their lives? Once these outcome measures are fully developed and tested, programmes such as MaiMwana or the Good Health for Women, would not only be assessed by the number of women saved from the maternal death road, or by the decreased incidence of HIV cases amongst a high-risk population. They could also be evaluated by capability sets expanded, or by units of subjective well-being gained. Economic evaluations that adopt these innovative outcome measures would be able to account for the effects of empowerment on people's lives, and for what people really value.

\section{Notes}

\footnotetext{
${ }^{1}$ https://youtu.be/gS7fCvCle1k, last accessed 24/08/2018.

2 Job applicants, personal communication, 22 May 2018.
}

\section{References}

Anand, Paul, and Paul Dolan. 2005. "Equity, capabilities and health." Social Science \& Medicine 60 (2):219-222.

Brazier, John, and Aki Tsuchiya. 2015. "Improving cross-sector comparisons: going beyond the healthrelated QALY." Applied health economics and health policy 13 (6):557-565.

Clark, David A. 2003. "Concepts and perceptions of human well-being: Some evidence from South Africa." Oxford Development Studies 31 (2):173-196. 
Coast, J., R. Smith, and P. Lorgelly. 2008. "Should the capability approach be applied in Health Economics?" Health Economics 17 (6):667.

Coast, Joanna. 2004. "Is economic evaluation in touch with society's health values?" British Medical Journal 329 (7476):1233-1236. doi: 10.1136/bmj.329.7476.1233.

Coast, Joanna, Philip Kinghorn, and Paul Mitchell. 2015. "The development of capability measures in health economics: opportunities, challenges and progress." The Patient-Patient-Centered Outcomes Research 8 (2):119-126.

Cookson, Richard, Mike Drummond, and Helen Weatherly. 2009. "Explicit incorporation of equity considerations into economic evaluation of public health interventions." Health Economics, Policy and Law 4 (2):231-245.

Fathalla, M. 2012. On Safe Motherhood at 25 years: Looking back, moving forward. In Women's Health and Rights: Lectures, Speeches and Statements FIGO.

Greco, Giulia, Paula Lorgelly, and Inthira Yamabhai. 2016. "Outcomes in Economic Evaluations of Public Health Interventions in Low-and Middle-Income Countries: Health, Capabilities and Subjective Wellbeing." Health economics 25 (S1):83-94.

Greco, Giulia, Jolene Skordis-Worrall, and Anne Mills. 2018. "Development, Validity, and Reliability of the Women's Capabilities Index." Journal of Human Development and Capabilities:1-18. doi: 10.1080/19452829.2017.1422704.

Greco, Giulia, Jolene Skordis-Worrall, Bryan Mkandawire, and Anne Mills. 2015. "What is a good life? Selecting capabilities to assess women's quality of life in rural Malawi." Social Science \& Medicine 130:69-78.

Grewal, Ini, Jane Lewis, Terry Flynn, Jackie Brown, John Bond, and Joanna Coast. 2006. "Developing attributes for a generic quality of life measure for older people: Preferences or capabilities?" Social Science \& Medicine 62 (8):1891-1901.

Lewycka, Sonia, Charles Mwansambo, Mikey Rosato, Peter Kazembe, Tambosi Phiri, Andrew Mganga, Hilda Chapota, Esther Kainja, Marie-Louise Newell, Giulia Greco, Anni-Maria PulkkiBrännström, Jolene Skordis-Worrall, Stefania Vergnano, David Osrin, and Anthony Costello. 2013. "Effect of women's groups and volunteer peer counselling on rates of mortality, morbidity, and health behaviours in mothers and children in rural Malawi (MaiMwana): a factorial, cluster-randomised controlled trial." The Lancet 381 (9879):1721-1735.

Marmot, Michael 2015. The Health Gap: The Challenge of an Unequal World. London Bloomsbury.

Mbonye, Martin, Winifred Nalukenge, Sarah Nakamanya, Betty Nalusiba, Rachel King, Judith Vandepitte, and Janet Seeley. 2012. "Gender inequity in the lives of women involved in sex work in Kampala, Uganda." Journal of the international AIDS society 15:17365.

Peasgood, Tessa, JE Brazier, Clara Mukuria, and Donna Rowen. 2014. "A conceptual comparison of well-being measures used in the UK."

Rosato, M., G. Laverack, L. H. Grabman, P. Tripathy, N. Nair, C. Mwansambo, K. Azad, J. Morrison, Z. Bhutta, and H. Perry. 2008. "Community participation: lessons for maternal, newborn, and child health." The Lancet 372 (9642):962-971.

Rosato, Mikey, Charles Mwansambo, Sonia Lewycka, Peter Kazembe, Tambosi Phiri, F Malamba, MN Newell, D Osrin, and A Costello. 2011. "MaiMwana women's groups: a community mobilisation intervention to improve mother and child health and reduce mortality in rural Malawi." Malawi Medical Journal 22 (4).

Rosato, Mikey, Charles W Mwansambo, Peter N Kazembe, Tambosi Phiri, Queen S Soko, Sonia Lewycka, Beata E Kunyenge, Stefania Vergnano, David Osrin, and Marie-Louise Newell. 2006. "Women's groups' perceptions of maternal health issues in rural Malawi." The Lancet 368 (9542):1180-1188.

Sassi, Franco, Leonard Archard, and Julian Le Grand. 2001. "Equity and the economic evaluation of healthcare." Health technology assessment (Winchester, England) 5 (3):1. 
Simon, Judit, Paul Anand, Alastair Gray, Jorun Rugkåsa, Ksenija Yeeles, and Tom Burns. 2013. "Operationalising the capability approach for outcome measurement in mental health research." Social Science \& Medicine 98:187-196.

Smith, R. , P. Lorgelly, Hareth Al-Janabi, Sridhar Venkatapuram, and J. Coast. 2012. "The Capability Approach: an alternative evaluation paradigm for health economics?" In The Elgar Companion to Health Economics, edited by Jones A., 415 - 424. Cheltenham, UK: Edward Elgar

Vandepitte, Judith, Justine Bukenya, Helen A Weiss, Susan Nakubulwa, Suzanna C Francis, Peter Hughes, Richard Hayes, and Heiner Grosskurth. 2011. "HIV and other sexually transmitted infections in a cohort of women involved in high risk sexual behaviour in Kampala, Uganda." Sexually transmitted diseases 38 (4):316.

World Bank. 2014. "Life time risk of maternal death ( 1 in: rates varies by country)." https://data.worldbank.org/indicator/SH.MMR.RISK. Last accessed 5 September 2018. 